\title{
DISCLAIMER
}

This report was prepared as an account of work sponsored by an agency of the United States Government. Neither the United States Government nor any agency thereof, nor any of their employees, makes any warranty, express or implied, or assumes any legal liability or responsibility for the accuracy, completeness, or usefulness of any information, apparatus, product, or process disclosed, or represents that its use would not infringe privately owned rights. Reference herein to any specific commercial product, process, or service by trade name, trademark, manufacturer, or otherwise does not necessarily constitute or imply its endorsement, recommendation, or favoring by the United States Government or any agency thereof. The views and opinions of authors expressed herein do not necessarily staie or reflect those of the United States Government or any agency thereof.

ANL/ CP- -73478

DE92 005240

\section{REVIEW OF THE COST-EFFECTIVENESS OF EPA'S OFFSHORE OIL AND GAS EFFLUENT GUIDELINES}

\author{
John A. Veil \\ Environmental Assessment and Information Sciences Division \\ Argonne National Laboratory \\ Washington, DC 20024
}

\section{INTRODUCTION}

The United States Environmental Protection Agency (EPA) published proposed Effluent Limitation Guidelines and New Source Performance Standards for the Offshore Subcategory of the Oil and Gas Extraction Point Source Category on March 13, 1991 (56 FR 10664). These guidelines include limitatious for Best Practicable Technology (BPT), Best Conventional Technology (BPT), Best Available Technology (BAT), and New Sn'-:ce Performance Standards (NSPS) for produced water, drilling fluids, drill cu'ungs, well treatment fluids, deck drainage, produced sand, and sanitary and d,restic waste.

As a support document to these regulations, EPA published a Cost-Effectiveness (CE) Analysis (EPA, 1991). This report calculated the CE of several different BAT and NSPS treatment options for produced water and drilling fluids and drill cuttings. Separate calculations were made for restricted versus unrestricted drilling rights and for three different oil costs per barrel. Each treatment option has a different cost and will result in removal of different levels of pollutants. The report calculates the annualized cost for each option and the pound equivalents (PE) removed and expresses the $C E$ as $\$ / P E$. The $C E$ value for the selected treatment option can be compared to the CE statistics from other industries for which EPA has done tine analysis. While not officially required for decision-making, as long as the CE: falls within some reasonable range, the selected treatment option is considered acceptable.

This paper examines the premises and assumptions used in the $\mathrm{CE}$ analysis and recalculates the $\mathrm{CE}$ statistic using alternate assumptions.

\section{EPA'S CE METHODOLOGY}

Ehrensberger and Rico (1988) describes and provides guidance on how to use EPA's CE methodology. CE is defined as the incremental annualized cost of a pollution control option in an industry or industry subcategory per incremental

$$
\text { 告 }
$$


pound equivalent of pollutant removed annually by that control option. When calculating annual pollutant removal, the relative strengths of the different pollutants must be considered. A pound of chromium will be far more harmful to the environment than a pound of iron. One way of scaling different pollutants is to assign a weighting factor to each pollutant based on its toxicity. EPA's methodology calculates weighting factors using EPA's ambient water quality criteria for chronic aquatic life protection (fresh or salt water) and for human health protection through fish consumption. For carcinogenic pollutants, the risk factor is taken as $10^{-5}$. All pollutants are normalized to a standard of $5.6 \mathrm{ppb}$, the aquatic life protection criterion for copper at the time the methodology was developed. Equation 1 shows the formula used.

$$
\text { weighting factor }=5.6 / \mathrm{AL}+5.6 / \mathrm{HH} \text {, where }
$$

$\mathrm{AL}=$ aquatic life protection criterion and

$\mathrm{HH}=$ human health protection criterion.

Two examples are shown below.

$$
\begin{array}{ll}
\text { Nickel } & 5.6 / 100+5.6 / 8.3=0.73 \\
\text { Mercury } & 5.6 / .025+5.6 / .146=262.4 .
\end{array}
$$

A more toxic pollutant will have lower criteria resulting in a higher weighting factor.

The next step in the procedure is multiplication of the actual pounds removed by the weighting factors to get $P E$ removed. Since $C E$ is calculated on an incremental basis, the PE must be calculated separately for each treatment option. The incremental PE is the PE for the option under consideration minus that for the next less stringent option. Costs must also be calculated on an incremental basis. The incremental $\mathrm{CE}$ is then calculated by dividing the incremental annualized cost by the incremental PE. Tables 4-1 through 4-14 in EPA (1991) contain the results of EPA's calculations for the different options. In the $C E$ analysis, all costs are scaled to 1981 dollars to allow comparison to the statistics calculated for other industries.

The list of pollutants used in the CE analysis is not limited to those pollutants regulated by the effluent guidelines. The list will also contain selected other toxics or non-conventional non-toxics which will be removed by a treatment option. For example, for drilling fluids and drill cuttings, only mercury and cadmium are limited in the effluent guidelines, but many other metals are also present and will be removed by the treatment options.

\section{EPA'S CONCLUSIONS}

In the March 13, 1991 proposed effluent guidelines, EPA selected treatment options for each waste stream. For drilling fluids and drill cuttings, wells from $0-4$ miles from shore may not discharge at all, and wells greater than 4 miles from shore have limits for mercury and cadmium of $1 \mathrm{mg} / \mathrm{kg}$. For produced water, wells from $0-4$ miles from shore must meet very stringent limits for oil and grease which EPA believes will require membrane filtration, and wells greater than 4 miles from shore 
must meet less stringent standards which do not require any additional treatment.

EPA performed the CE analysis for each waste stream and found that BAT and NSPS for drilling fluids and drill cuttings would cost $\$ 22 / \mathrm{PE}, \mathrm{BAT}$ for produced water would cost $\$ 60 / \mathrm{PE}$, and NSPS for produced water would cost $\$ 63 / \mathrm{PE}$. CE statistics for twenty other industries range from less than one dollar to $\$ 404 / \mathrm{PE}$ (EPA, 1991). Therefore EPA was satisfied that the treatment options selected for drilling fluids and drill cuttings and produced water were not unreasonable from a $\mathrm{CE}$ perspective.

\section{DISCUSSION OF EPA'S ASSUMPTIONS}

There are several assumptions used in the CE methodology which warrant discussion. Some of these are applicable to all industries and others are only relevant to the offshore oil and gas industry. The first category of assumptions represents shortcomings in EPA's CE methodology, but since they have been consistently applied to all other industries for which a $\mathrm{CE}$ analysis has been done, they are not the subject of this paper and will be discussed only briefly.

\section{GENERAL SHORTCOMINGS IN CE METHODOLOGY}

This category includes: the approach of using weighting factors to account for different environmental impacts of various pollutants; the need to sum the effect of aquatic life protection criteria and human health protection criteria; the use of an incremental approach rather than a cumulative approach; and the failure to consider the form of metal used in the calculations.

\section{Using Weighting Factors}

It is desirable to equitably account for the wide range of toxicities found among chemicals, but the methodology used to weight different pollutants must be reasonable or the resulting weighted pollutant loads will not be meaningful. The approach used in EPA's CE methodology is plausible and is based on a set of generally consistently derived uriteria.

One weakness is the absence of a complete set of EPA criteria. A complete set of criteria for a pollutant includes freshwater and marine acute criteria, freshwater and marine chronic criteria, and human health criteria from fish consumption and from fish consumption and drinking water intake. While EPA has developed criteria for over 100 pollutants, many of those criteria sets are incomplete, especially for the chronic or human health criteria which are used in the CE methodology. Ehrensberger and Rico (1988) advises that the person conducting the CE analysis contact EPA's Criteria and Standards Division for some less rigorously derived "criterion" or to otherwise estimate the criterion value. No specific guidance is given on how the person should estimate the criterion, lending some doubt to the reliability of the subsequent weighting factor.

Another weakness of using EPA criteria is that those criteria are technical recommendations, not adopted standards. As such, they have not faced full regulatory scrutiny. Following the Water Quality Act of 1987 , as states were 
required to adopt water quality standards for many toxic standards, some of the EPA criteria were seriously questioned by both states and the regulated community. One important example of this is the human health criterion for arsenic. Murphy (1990) provides substantial evidence that the arsenic criterion is based on invalid conclusions and is overly stringent. This is particularly noteworthy since the actual criterion value for arsenic is one of the lowest $(0.175 \mathrm{ppb})$ and it results in a relatively high weighting factor.

EPA (1991a) recommends updating human health criteria by using the latest risk assessment information from the Integrated Risk Information System (IRIS). EPA (1991) has followed this guidance and has updated many of the human health criteria for pollutants used in the CE analysis for the offshore oil and gas industry. While using up-to-date information is desirable, this practice creates two problems. The data is not fully peer reviewed and subjected to EPA's formal criteria development procedures, leaving the numbers open to criticism. By using changed criteria, newer CE analyses can no longer be equitably compared to earlier $C E$ analyses. Tabie 1 shows both the published and recalculated human health criteria for all pollutants considered in the $\mathrm{CE}$ analysis for produced water in the offshore industry.

\section{Summing Criteri乏}

Ehrensberger and Rico (1988) specifies that the weighting factor should be calculated separately for both the aquatic life and human health criteria and then should be summed (see equation 1). This practice serves to make the weighting factor larger, especially if the two criteria are approximately equal. It makes more sense to use whichever of the two criteria is most restrictive and base the weighting factor on only that single number.

\section{Incremental Approach}

Ehrensberger and Rico (1988) requires that CE should be calculated on an incremental basis. When several treatment options are being considered, costs and PE removed are calculated for each option. \$/PE are then incrementally calculated. This approach is dependent on the number of options under consideration. While for most industries only a few treatment options are considered, the more options that are considered, the less meaningful the incremental approach becomes. As an extreme example, consider 100 treatment options each one marginally more restrictive than the previous one. Imagine that cadmium and mercury limits for drilling fluids and drill cuttings could be established anywhere from $0.5 \mathrm{mg} / \mathrm{kg}$ to $10.5 \mathrm{mg} / \mathrm{kg}$ at increments of $0.1 \mathrm{mg} / \mathrm{kg}$. This creates 100 possible regulatory options. The incremental \$/PE are going to be very small and not very useful. A more logical approach would be to calculate the cumulative $\$ / P E$ for each option. This approach would provide obvious breakpoints in $C E$, and allow selection of the most appropriate treatment option.

\section{Form of Metals}

As the emphasis on toxics has increased, greater attention has been focused on analytical methods for metals. Most metals can be analyzed in several ways using different sample preparation techniques. The most common metal forms in order of increasing portions of the total metai present are dissolved, acid soluble, total 


\section{Table 1 - Criteria Used for Toxic Weighting Factors}

Produced Water

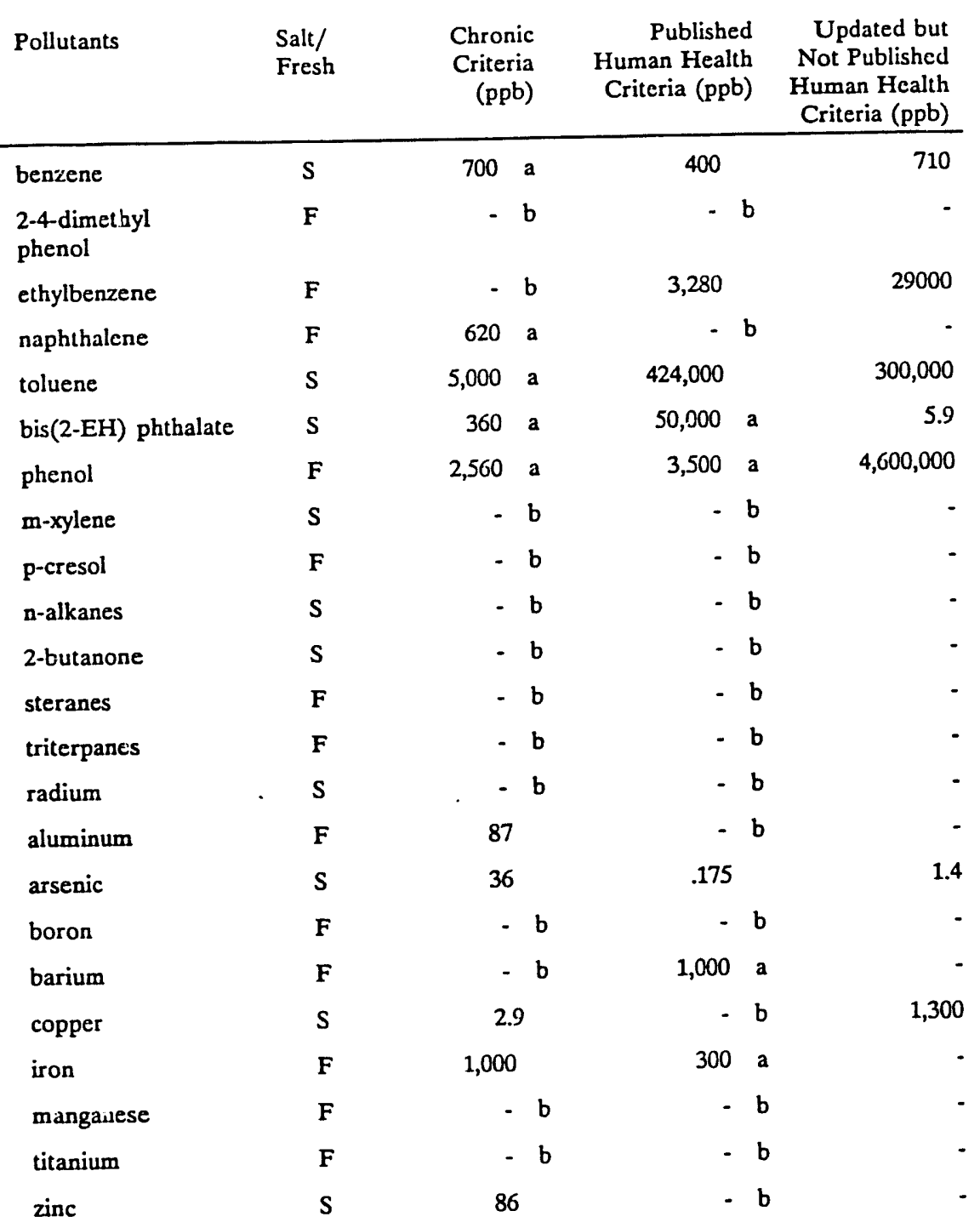

a - published criterion available and shown here, but EPA used another value instead b - no published criterion available 
recoverable, and total. Most of EPA's aquatic life criteria are based on and expressed as the acid soluble form as this more closely approximates the way metals are encouniered by biota in the environment. On the other hand, permit limits and probably the pounds of pollutants removed by the various treatment options considered in a CE analysis are measured as total or total recoverable metals.

There is very little information available about the ratio between acid soluble and total metals. Battelle Ocean Systems has conducted a sampling program in New York Harbor and the preliminary results suggest that there is very little difference between acid soluble and total recoverable metals ${ }^{1}$. Brumfield (1988) studied treated municipal wastewater and sludge from eight cities in Indiana and found very little difference between acid soluble and total metals in the treated wastewater, but in the sludge analysis, the acid soluble test results ranged from $9-90 \%$ of the total metal results. Another source of data comes from the Hart-Miller Island Dredged Material Disposal Facility in Chesapeake Bay near Baltimore Harbor (Stone, 1991). A summary of eight samples found that acid soluble metals values are from 45 $59 \%$ of total metals values.

This limited data suggests that when metals are associated with elevated solids levels the acid soluble measurement declines noticeably compared to the total metal measurement. The ratio will vary depending on the suspended solids and water chemistry of the receiving water, but it is clear that the biologically available pounds of metals discharged are less than the total pounds of metals. Thus a more environmentally accurate \$/PE for acid soluble metals will be higher than the regular $\$ / \mathrm{PE}$ for total metals.

\section{SHORTCOMINGS IN EPA'S CE METHODOLOGY SPECIFIC TO THE OFFSHORE OIL AND GAS INDUSTRY}

The offshore oil and gas industry is unique among major industries in that all regulated operations are located away from land and are in a marine environment. No other major industrial category has all its members discharging to salt water or facing the space and logistical problems inherent to the offshore industry. These factors need to be considered in developing not only the $C E$ analysis, but in selecting a treatment option as well. There are three shortcomings in EPA's CE analysis which are specific to the offshore oil and gas industry. These are the availability and stringency of marine chronic criteria compared to fresh water chronic criteria, failure to consider the vast dilution found at an offshore oil or gas platform, and the use of human health criteria for determining weighting factors when the discharges are short-lived. The first two issues will be discussed briefly and a detailed recalculation of weighting factors is provided for the third issue.

\section{Marine vs. Fresh Water Crit •ria}

EPA has developed 67 fresh water chronic criteria, but only 42 marine chronic criteria (EPA, 1986). For many of the pollutants chosen for the $C E$ analysis, no marine chronic criterion exists, and some alternative, less structured "criterion" must be chosen to develop weighting factors.

\footnotetext{
${ }^{1}$ Personal communication with Damian Shea, Battelle Ocean Systems, Duxbury, MA on May 1, 1991
} 
The actual values for marine criteria are smaller than the fresh water criteria for the same pollutants in some cases. This is not necessarily due to an inherently higher toxicity of the pollutants in marine waters, but rather to a feature of the criterion derivation procedure. Calculation of chronic criteria involves statistical analysis of chronic toxicity data which is sensitive to the number of species tested (EPA, 1985). When fewer species are tested, the uncertainty that the data represents a wide range of species remains high and the criterion is increased accordingly. Historically, there have been far more aquatic toxicity tests conducted on fresh water species than on marine species. By virtue of the smaller number of available marine test results to be used in the calculations, a marine criterion will be lower than the corresponding fresh water criterion even if the most sensitive species in both sets of data show exactly the same toxicity results.

The impact on the offshore oil and gas industry is that weighting factors can be higher than they would be for an industry discharging into fresh water, due to a lack of data. It is not feasible to quantify the effect that this has on the CE statistics.

\section{Dilution in the Offshore Environment}

Normally a CE analysis does not consider dilution of the discharged pollutants, but in the offshore environment the dilution is extremely large and warrants evaluation. Discharging 10 pounds of copper into a small stream or river may be important to the local ecosystem, but discharging the same amount of copper at a well several miles offshore has virtually no impact on the local ecosystem. Dilution can be calculated by equation 2 .

$$
\begin{aligned}
& \text { dilution }=(\mathrm{V} \times \mathrm{DxW}) / \mathrm{Qe}, \text { where: } \\
& \mathrm{V}=\text { ambient tlow velocity } \\
& \mathrm{D}=\text { water depth } \\
& W=\text { width of zone of dilution } \\
& \mathrm{Qe}=\text { effluent flow }
\end{aligned}
$$

Ambient flow velocity is variable with weather conditions and depth. Ecomar (1980) reported offshore currents near a Gulf of Mexico drilling platform from 0 $30 \mathrm{~cm} / \mathrm{sec}$, and above the bottom, the lowest velocity was $3 \mathrm{~cm} / \mathrm{sec}$. O'Reilly et al (1989) found surface currents near a California offshore platform from $2.5-7.2$ $\mathrm{cm} / \mathrm{sec}$ and bottom currents of $1.5-4.1 \mathrm{~cm} / \mathrm{sec}$. A conservative velocity of 1.5 $\mathrm{cm} / \mathrm{sec}$ is assumed here.

Water depth is also variable; the proposed effluent guidelines define shallow water as $20 \mathrm{~m}$ or less. EPA (1991b) reports that for the Gulf of Mexico only $10-37 \%$ of all new wells will be drilled in shallow water. Nevertheless, a depth of $20 \mathrm{~m}$ is used for the dilution calculation. Other wells would have even greater dilution. There is no particular convention for selecting a zone of dilution width. Two widths, $200 \mathrm{~m}$ and $1000 \mathrm{~m}$, were used in the dilution calculation. They represent affected radii of $100 \mathrm{~m}$ and $500 \mathrm{~m}$ respectively.

The average daily effluent flow for drilling fluids and drill cuttings in the Gulf of Mexico is $163 \mathrm{bbl} /$ day (EPA, 1991b). For produced water, the average daily discharge is less than $1800 \mathrm{bbl} /$ day, but some large facilities may discharge as much as $157,000 \mathrm{bbl} /$ day (Walk, Haydol \& Associates, 1984). 
These assumptions result in dilutions of $200,000: 1$ for a dilution zone width of 200 $\mathrm{m}$ and $1,000,000: 1$ for $1000 \mathrm{~m}$ width for drilling fluids and drill cuttings. For produced water, the dilutions are 18,126:1 and 90,629:1 respectively for the average discharge volume, and 208:1 and 1038:1 respectively for the maximum daily discharge.

Even the smallest of these dilution ratios is significant and the larger dilution ratios are so high that they should be considered in assessing the true environmental impact of the pounds or PE discharged. When diluted to the extent predicted by these calculations, many of the pollutants will be nondetectable and very few if any will be biologically harmful.

\section{Applicability of Human Health Criteria for Calculation of Weighting Factors}

Ehrensberger and Rico (1988) requires that the weighting factor be based on both chronic aquatic life protection and human health criteria. Clearly using the chronic criterion is appropriate for protecting the ecosystem, but when the assumptions used to derive a human health criterion are considered, its use is questionable for the offshore oil and gas industry. A human health criterion is based on exposure to a given quantity of the pollutant for a 70 year period (EPA, 1991a). For many land-based dischargers, their discharge will continue in the same location for many years, and the 70 year assumption is reasonable. In the offshore oil and gas industry, the discharges are shorter in duration, especially discharges of drilling fluids and drill cuttings.

EPA (1991b) reports that the average total volume of drilling fluids and drill cuttings from a Gulf of Mexico well is $8379 \mathrm{bbl}$, and that the average daily discharge is $163 \mathrm{bbl}$. This yields an average period of discharge of 51.5 days. The duration of produced water discharge depends on the productivity of the well. At the start of oil or gas production, the proportion of pioduced water is small, but as the reservoir becomes depleted, the proportion of produced water increases until at some point the amount of oil and gas produced becomes uneconomical and the well is closed. A typical duration of produced water discharge is about 15 years per field ${ }^{2}$.

The duration of both waste streams is significantly less than 70 years and therefore the weighting factor should not be calculated using the human health criterion. The weighting factors used in EPA (1991) have been recalculated using only the chronic aquatic life protection criteria whenever possible. Marine chronic criteria were used if available. If not, fresh water chronic criteria were used. If no chronic criterion was available, the value used by EPA was also used here.

Table 2 shows the EPA and revised toxic weighting factors for BAT for produced water. Table 2 also provides revised PE loads calculated using the revised weighting factors. Similar calculations were made for drilling fluids and drill cuttings (NSPS - restricted, and NSPS - unrestricted) and for produced water (NSPS - restricted, and NSPS - unrestricted). Due to space limitations, these are not reproduced in this paper.

\footnotetext{
${ }^{2}$ Personal communication with Tom Randolph, Senior Staff Environmental Engineer, Shell Offshore, Inc. April 25, 1991
} 
Table 2 - Toxic Weighting Factors and Pound Equivalents

\begin{tabular}{|c|c|c|c|c|c|}
\hline \multirow[b]{2}{*}{ Pollutants } & \multicolumn{3}{|c|}{ Produced Water - BAT } & \multirow[b]{2}{*}{$\begin{array}{r}\text { EPA } \\
\text { Equivalents } \\
\text { Removed } \\
(\mathrm{PE} / \mathrm{yr}) \\
\end{array}$} & \multirow[b]{2}{*}{$\begin{array}{r}\text { Revised } \\
\text { Equivalents } \\
\text { Removed } \\
(\mathrm{PE} / \mathrm{yr})\end{array}$} \\
\hline & $\begin{array}{r}\text { Pollutants } \\
\text { Removed } \\
(\mathrm{lb} / \mathrm{yr})\end{array}$ & $\begin{array}{r}\text { EPA Toxic } \\
\text { Wcighting } \\
\text { Factor }\end{array}$ & $\begin{array}{r}\text { Revised } \\
\text { Toxic } \\
\text { Weighting } \\
\text { Factor } \\
\end{array}$ & & \\
\hline benzenc & 58471 & .036 & .008 & 2,105 & 468 \\
\hline $\begin{array}{l}\text { 2-4-dimcthyl } \\
\text { phenol }\end{array}$ & 458 & .0056 & .006 & 3 & 3 \\
\hline ethylbenzene & 16148 & .262 & .001 & 4,231 & 16 \\
\hline naphthalene & 4411 & 1.47 & .009 & 6,484 & 40 \\
\hline toluene & 49387 & .0018 & .001 & 89 & 49 \\
\hline bis(2-EH) phthalate & 3226 & .097 & .016 & 313 & 52 \\
\hline phenol & 30446 & .0193 & .002 & 588 & 61 \\
\hline m-xylene & 4888 & .160 & .160 & 782 & 782 \\
\hline p-cresol & 11640 & .007 & .007 & 81 & 81 \\
\hline n-alkanes & 52482 & .074 & .074 & 3,884 & 3,884 \\
\hline 2-butanone & 53357 & .0001 & .0001 & 5 & 5 \\
\hline steranes & 2012 & .074 & .074 & 149 & 149 \\
\hline triterpanes & 2429 & .074 & .074 & 180 & 180 \\
\hline radium & .0135 & 1060000 & $1060000^{a}$ & $14,310^{b}$ & 14,310 \\
\hline aluminum & 1648 & .037 & .064 & 61 & 105 \\
\hline arsenic & 4172 & 32.16 & .155 & 134,172 & 647 \\
\hline boron & 4374 & .177 & .177 & 774 & 774 \\
\hline barium & 51305 & .002 & .002 & 103 & 103 \\
\hline copper & 1514 & 1.93 & 1.93 & 2,922 & 2,922 \\
\hline iron & 42726 & .0056 & .0056 & 239 & 239 \\
\hline manganese & 269 & .056 & .0144 & 15 & 4 \\
\hline titanium & 114 & .029 & .029 & 3 & 3 \\
\hline zinc & 78589 & .065 & .065 & 5,108 & 5,108 \\
\hline Total & & & & 176,601 & $29,985^{c}$ \\
\hline
\end{tabular}

a 122,000 - recalculated toxic weighting factor for radium

b 1,647 - reflects recalculated toxic weighting factor for radium

c 17,322 - reflects recalculated toxi - weighting factor for radium 
Table 3 provides a comparison of EPA PE loads, revised PE loads, EPA \$/PE, and revised $\$ / P E$ for each option. The revised PE loads were in all cases much less than EPA's PE loads and the revised \$/PE were much greater than EPA's \$/PE.

It is interesting to note that the pollutant most affected by the recalculation procedure is arsenic. In the EPA PE loads, arsenic makes up from 10 to $76 \%$ of the total load, but in the revised loads, arsenic is never more than $2.1 \%$ of the total load. This reduction is attributable to the extremely low human health criterion for arsenic. As discussed earlier, Murphy (1990) points out the shortcomings of the arsenic human health criterion. If this suspect criterion is not included in the analysis, the weighting factor becomes much more moderate.

While the need to use criteria values derived from outside sources and not true criteria is understandable when no criteria are available, EPA did not use published criteria to calculate the weighting factors for a number of pollutants, even when they were available. The cases for which EPA used an amended criterion when a published criterion was available, and when no published criterion was available are indicated on Table 1. Instead, EPA relied on some outside source of information which was not documented in EPA (1991) or elsewhere in the official record. The resulting numbers were listed in several tables found in the official record (EPA, 1990) without any accompanying report or explanation of how they were derived. Most likely, the amended numbers were based on more current information which was not extensive enough to allow formal criterion development and may have come from the AQUIRE data base or from some other source. Often the data was in the form of an LC50, an acute toxicity statistic, and not a chronic toxicity result ${ }^{3}$.

By using the amended data for some pollutants, EPA has deviated from the specified procedures in Ehrensberger and Rico (1988). Since the amended values are almost all more stringent than the official criteria, the resulting weighting factors become higher.

The use of numbers other than true criteria creates some uncertainty, especially when the pollutant in question represents a substantial portion of the total load. In the case of produced water two pollutants make up $60 \%$ of the revised total PE load -- radium (47\%) and n-alkane (13\%). But criteria are not available for either of these so EPA relied on amended data. The radium data is solely human health data, and no information is given on the derivation of the n-alkane data. When important components of the PE load are based on either inappropriate or linexplained data, the total PE load becomes questionable.

EPA's calculation of toxic weighting factors for radium 226 and 228 was not found in the public record, but rather was an unpublished memorandum (EPA, 1990). In this document, EPA used safe drinking water concentrations of $2.1 \mathrm{pCi} / 1$ for radium 226 and $2.8 \mathrm{pCi} / \mathrm{l}$ for radium 228. Since then, EPA has proposed National Primary Drinking Water Regulations for radionuclides ${ }^{4}$ which establish drinking water standards for radium 226 and 228 of $20 \mathrm{pCi} / \mathrm{l}$. This corresponds to risk levels of

\footnotetext{
${ }^{3}$ Personal communication, Alexandra Tarnay, Assessment and Watershed Protection Division, EPA, April 29, 1991 and May 3, 1991

"July 18, 1991 Federal Register, 56 FR 33050
} 
Table 3 - Comparison of PE Loads and \$/PE

\begin{tabular}{llll}
\hline EPA PE Load & Revised PE Load & EPA \$/PE & Revised \$/PE \\
(PE/year) & (PE/year) & $(1981 \$)$ & (1981 \$)
\end{tabular}

Drilling Fluids and Cuttings

$\begin{array}{lllll}\text { NSPS - Unrestricted } & 491,192 & 329,818 & \$ 28 & \$ 42 \\ \text { NSPS - Restricted } & 442,493 & 330,227 & \$ 22 & \$ 29\end{array}$

Produced Water

$\begin{array}{lllcl}\text { BAT } & 176,601 & 29,985[17322] & \$ 60 & \$ 355[\$ 615] \\ \text { NSPS - Unrestricted } & 350,240 & 59,400[34355] & \$ 40 & \$ 237[\$ 410] \\ \text { NSPS - Restricted } & 140,065 & 23,776[13739] & \$ 63 & \$ 372[\$ 644]\end{array}$

[ ]- reflects recalculated toxic weighting factor for radium

$10^{-4}$ and $8 \times 10^{-5}$ respectively. Although the CE methodology calls for a risk level of $10^{-5}$, if EPA is willing to use a less stringent risk level in its national drinking water regulations, that same level should be acceptable here. The revised toxic weighting factor for radium (average of 226 and 228) is $1.22 \times 10^{-5}$. Since radium accounted for $47 \%$ of the revised total load for produced water, an 8.7 fold reduction in its toxic weighting factor will have a marked effect. The revised PE loads decrease by an additional $42 \%$ when the radium toxic weighting factor is recalculated, as shown in Table 3.

The earlier $\mathrm{CE}$ analyses dealt primarily with the priority pollutants and mainly the heavy metals. But more recently, the list of pollutants considered has been expanded to include other non-priority pollutants and nonconventional non-toxics (Ehrensberger and Rico, 1988). Many of the pollutants considered in the CE analysis for the offshore oil and gas industry fall in these latter categories. This represents one more way in which the total PE load for the offshore industry is not completely comparable to some of the other industries for which the $\mathrm{CE}$ analysis has been conducted. Since more PE are contributed by these additional pollutants, the $\$ / P E$ will be proportionately lower than for some of the earlier analyses.

Although offshore oil and gas industry discharges do not continue for 70 years, there is some concern that the discharged pollutants may enter the food chain and be subject to bioaccumulation, the uptake and retention of a chemical in animal tissues from external sources. This could lead to human health effects through consumption of fish and shellfish exposed to offshore industry discharges. Neff (1988) reviewed the available literature concerning the potential for bioaccumulation of toxic constituents of drilling and production wastes in estuarine 
and marine food chains and reported that although produced water contains various alkanes and aromatic hydrocarbons which are rapidly bioaccumulated by marine organisms, these chemicals are not persistent in animal tissue. Half times for release of the accumulated hydrocarbons ranges from less than one day to ten days. Biomagnification, a type of bioaccumulation in which the concentration of a pollutant increases at each higher trophic level in the food chain, does not occur because most marine animals have only a limited ability to accumulate toxics from their food and all species are able to rapidly clear their tissues of hydrocarbons.

Neff also found that metals in drilling fluid discharges are primarily in an insoluble form. Even though they may be bioaccumulated to a limited extent, since they are in the insoluble form, they have low toxicity to marine organisms. Biomagnification of the metals does not occur. Since biomagnification does not occur for either the hydrocarbons or metals, there is little likelihood that fish and shellfish exposed to offshore industry discharges and later consumed by humans will cause any health effects.

The revised numbers presented in this paper represent an attempt to amend the CE procedure to be more representative of the specific environmental setting experienced by the offshore oil and gas industry. Even though the revised calculations must, by necessity, rely on some human health numbers or on some of EPA's amended numbers in the absence of chronic aquatic life protection numbers, the revised \$/PE still increases dramatically, especially for produced water.

The produced water revised value for BAT is $\$ 355$ which is higher than the $\$ / P E$ for all but one of the other industries which have been tested. A comparison of \$/PE for the different industries is given in Table 4. The Electronics I industry has a $\$ / P E$ of $\$ 404$, but that industry is substantially smaller than the offshore oil and gas industry. A total of only $9000 \mathrm{PE}$ per year were discharged prior to BAT being implemented compared to 6.9 million PE per year for produced water. The economic impacts are disproportionate for the two industries. No other industry has a BAT \$/PE which is even close to these two. The recalculated \$/PE due to the revised radium toxic weighting factor becomes $\$ 614$ which is clearly higher than anything else considered.

For NSPS, the comparison is even more striking. The revised $\$ / P E$ for both the restricted and unrestricted options, $\$ 372$ and $\$ 237$ respectively, are higher than those for any other industry. This becomes even more distinctive when the $\$ / P E$ are recalculated using alternate toxic weighting factors for radium. The $\$ / P E$ are $\$ 644$ and $\$ 409$ respectively.

\section{CONCLUSIONS}

The CE methodology assigns weights to the different pollutants which will be removed by the treatment options under consideration. The procedure for caiculating weighting factors has some overall limitations, but some of them are common to all of the $\mathrm{CE}$ analyses done thus far and are therefore consistent limitations. There are other features of the CE methodology which are specifically inappropriate to the offshore oil and gas industry. The easiest to quantify is the weighting factor calculation procedure. Considering that discharges from offshore platforms are relatively short-lived, the use of human heaith criteria, which are based on a 70 year exposure, to calculate the weighting factors is misleading and 
Table 4 - Comparison of Cost-Effectiveness Among Industries (based on EPA, 1991)

\section{Industry}

Aluminum Forming

Battery Manufacturing

Canmaking

Coal Mining

Coil Coating

Copper Forming

Electronics I

Electronics II

Foundries

Inorganic Chemicals I

Inorganic Chemicals II

Iron and Steel

Leather Tanning

Metal Finishing

Nonferrous Metals Forming

Nonferrous Metals Manufacturing I

Nonferrous Metals Manufacturing II

Organic Chems., Plastics, \& Synthetics

Pesticides

Petroleum Refining

Pharmaceuticals

Plastics Molding and Forming

Porcelain Enameling

Pulp and Paper

Textile Mills

Offshore Oil and Gas

produced water - EPA
produced water - revised
produced water - (reflects
revised toxic weighting
factor for radium)
drilling fluids - EPA
drilling fluids - revised

\section{\$/PE (BAT)}

121
2
10
BAT $=\mathrm{BPT}$
49
27
404
-
84
$<1$
6
2
BAT $=\mathrm{BPT}$
12
69
4
6
5
15
BAT $=\mathrm{BPT}$
1
BAT $=\mathrm{BPT}$
6
18
BAT $=\mathrm{BPT}$

60

355

615
S/PE (NSPS)

190

47

-

13

132

183

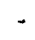

-

-

$<1$

-

9

-

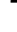

-

38

-
40 (unrestricted)
63 (restricted)
237 (unrestricted)
372 (restricted)
410 (unrestricted)
644 (restricted)
28 (unrestricted)
21 (restricted)
42 (unrestricted)
29 (restricted)


overestimates the relative impact of many pollutants. When weighting factors are recalculated using only chronic aquatic life protection criteria whenever possible, the PE loads decrease dramatically and the $\$ / P E$ increase. For produced water, the increased $\$ / P E$ becomes su high that they are no longer comparable with the $\$ / P E$ for other industries.

When this incongruity is coupled with the vast dilution present in the offshore environment, the costs for treatment of wastes which have limited environmental impact outside of a small zone of dilution and which will impact only a geographically minuscule percentage of the offshore ecosystem represents an unreasonable burden on the industry.

\section{ACKNOWLEDGEMENTS}

This work was supported by the U. S. Department of Energy, Office of Policy, Planning and Analysis, under contract W-31-109-Eng-38.

\section{REFERENCES}

Brumfield, L., 1988, Comparing total metals to acid soluble metals, Presented at the August 15, 1988 Indiana Water Pollution Control Association Annual Conference.

Ecomar, 1980, "Maximum Mud Discharge Study", for the Offshore Operators' Committee under the direction of Exxon Production Research Co.

Ehrensberger, K. and R. Rico, 1988, "Cost-Effectiveness Analysis for Effluent Guidelines", U.S. Environmental Protection Agency.

EPA, 1985, "Guidelines for Deriving Numerical National Water Quality Criteria for the Protection of Aquatic Organisms and Their Uses", NTIS-PB85-227049.

EPA, 1986, "Water quality criteria summary", update 1.0, U. S. Environmental Protection Agency.

EPA, 1990, unpublished tables of toxic weights dated June 28, 1990 and July 17, 1990, U. S. Environmental Protection Agency.

EPA, 1991, "Cost-Effectiveness Analysis of Proposed Effluent Limitation Guidelines and Standards for the Offshore Oil and Gas Industry", EPA 440/2-91-002, prepared by Eastern Research Group, Inc.

EPA, 1991a, "Technical Support Document for Water Quality-based Toxics Control", EPA/505/2-90-001, U. S. Environmental Protection Agency.

EPA, 1991b, "Proposed Development Document for Effluent Limitation Guidelines and Standards for the Offshore Subcategory of the Oil and Gas Extraction Point Source Category", EPA 440/1-91/055.

Murphy, D., 1990, "Criteria issue: the necessity of a fish consumption criterion for arsenic", (unpublished report), Maryland Department of the Environment. 
Neff, J., 1988, "Bioaccumulation and Biomagnification of Chemicals from Oil Well Drilling and Production Wastes in Marine Food Webs: A Review", prepared by Battelle Ocean Sciences for American Petroleum Institute.

O'Reilly, J., T. Sauer, R. Ayers, Jr., M. Brandsma, and R. Meek, 1989, "Field verification of the OOC mud discharge model", in: "Drilling Wastes", Elsevier Applied Science, London and New York, pp. 647 - 665.

Stone, E., 1991, unpublished monitoring data for Hart-Miller Island Dredged Disposal Facility, Maryland Department of the Environment.

Walk, Haydel \& Associates, 1984, "Potential Impact of Proposed EPA BAT/NSPS Standards for Produced Water Discharges from Offshore Oil and Gas Extraction Industry", report to Offshore Operators Committee, New Orleans, LA. 

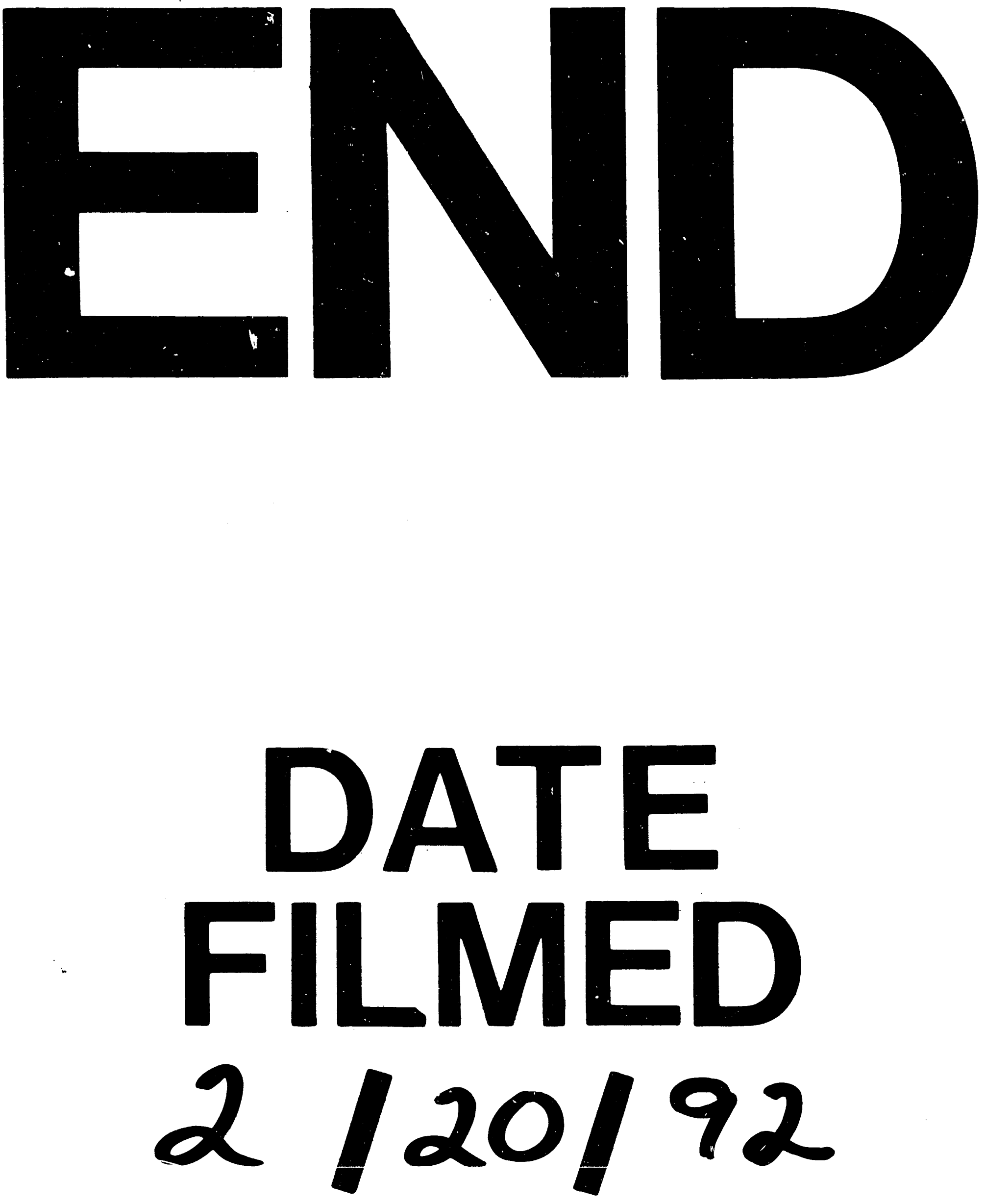
